\title{
Determination of Evapotranspiration and Water Use Efficiency in Crop Production
}

\author{
Kazeem 0. Rauff ${ }^{*}$, Saheed A. Shittu ${ }^{2}$ \\ ${ }^{1}$ Federal University, Kashere, Nigeria \\ ${ }^{2}$ Federal College of Animal Health \& Production Technology, Ibadan, Nigeria \\ Email: ${ }^{*}$ rauffkazeem@fukashere.edu.ng
}

Received 8 May 2015; accepted 23 September 2015; published 28 September 2015

Copyright (C) 2015 by authors and Scientific Research Publishing Inc.

This work is licensed under the Creative Commons Attribution International License (CC BY).

http://creativecommons.org/licenses/by/4.0/

(c) (i) Open Access

\begin{abstract}
The main concern in cultivating crops has always been water availability. To increase food production, water plays a major role after securing a large portion of land area. Knowledge of the factors influencing crop water use efficiency and hope to increase the efficiency has continued to be an objective in many modern studies. The gap between irrigation supply and demand is increasing from year to year as a result of an increase in population growing rate and people moving from place to place. Searching for new water may be a too difficult and very expensive process, so the shortest and easiest way is to maximize the water use efficiency throughout optimizing water use efficiency and the first step on that is determination of the actual crop water requirements.
\end{abstract}

\section{Keywords}

\section{Evapotranspiration, Micrometeorological, Bowen Ratio, Microclimate, Turbulent Transport}

\section{Introduction}

The crop evapotranspiration is defined like the water transferred to atmosphere by plant transpiration and surface evaporation. The evapotranspiration term was proposed by [1] to conceptualize the process of plant transpiration and surface evaporation which occurs simultaneously and no easy way to distinguish them. The evapotranspiration process occurs naturally only if there is inflow of energy in the system, from the sun, atmosphere, or both, and is controlled by the rate of energy in the form of water vapor that spreads from the surface of the Earth [2]. This transfer takes place physically in the forms of molecular and turbulent diffusion.

According to [3], evaporation is the process whereby liquid water is converted to water vapor (vaporization)

\footnotetext{
${ }^{*}$ Corresponding author.
} 
and removed from the evaporating surface (vapor removal). Water evaporates from a variety of surfaces, such as lakes, rivers, pavements, soils and wet vegetation. Transpiration, in turn, is the transfer of water from plants through their aerial parts. Water transfer from plant to atmosphere occurs mainly through the stomata through which they pass more than $90 \%$ water transpired.

The evapotranspiration can be derived from a range of measurement systems including lysimeters, eddy covariance, Bowen ratio, water balance (gravimetric, neutron meter, other soil water sensing), sap flow, scintillometer and even satellite-based remote sensing and direct modeling [4]. The micrometeorological method of Bowen Ratio Energy Balance (BREB) has been widely applied due to its relative simplicity, practicality, robustness and accuracy. Recently, the Eddy Covariance method has been increasingly applied mainly after the sensors have reduced costs.

The science of micrometeorology, which deals with atmospheric processes near the earth's surface, is providing increased knowledge of the mechanisms controlling our environment. Micrometeorological methods have only recently been applied to agronomic problems. Such application has increased our understanding of the response of crop plants to their physical environment, thereby permitting us to develop improved agronomic practices aimed at achieving more efficient use of water with increased and more economical production of crops [5].

The main aim of this discussion is to summarize some of the key factors in the application of the meteorological methods to agronomic problems. The application of the methods to the problems of increasing water-use efficiency and crop production will be emphasized rather than the details of the methods. This will include a review of some of the basic physical factors controlling the microclimate at any point on the earth's surface and the application of the meteorological approach in studying this microclimate [5].

The meteorological method has a twofold application to agronomic problems. First, it serves as a useful research tool, permitting the study of basic physical processes within the microclimate. Second, it has the potential for direct application to farm management practices, such as measurement of the evaporative loss of water and determination of when to irrigate. The expenditure of considerable time, effort and money in the development of these methods is fully justified because only by gaining an increased understanding of the natural physical environment of soils and plants and their response to this environment can we hope to understand and predict plant responses to microclimatic conditions. The resulting information will permit us to develop methods of altering the natural environment to increase crop production and water-use efficiency [5].

\section{Bowen Ratio Energy Balance (BREB)}

The Bowen-ratio method is one of the most common methods used to determine the fluxes of sensible and latent heat. The method is based on Bowen-ratio similarity and the energy balance equation. The energy balance equation provides a sound theoretical basis for estimating evaporation from natural surfaces. For a natural surface the complete equation can be written as

$$
Q_{s}^{*}=Q_{H}+Q_{E}+Q_{G}+Q_{V}+Q_{W}+Q_{P}
$$

where:

$Q_{H}=$ turbulent transfer of sensible heat flux which is responsible for heating the atmosphere from the surface up to some $100 \mathrm{~m}$ during the day, except for days with strong convection,

$Q_{E}=$ latent heat energy loss by evapotranspiration,

$Q_{G}=$ vertical heat flux downward into the ground,

$Q_{V}=$ horizontal heat flux, or advection, out of the region,

$Q_{W}=$ net heat loss due to vertical water storage exchange,

$Q_{P}=$ net energy used in such natural processes as photosynthesis.

The vertical water storage exchange term refers to the transfer through evaporation and precipitation at temperature different than the mean surface temperature. The relative magnitudes of terms in equation above are highly dependent on the space and time scales under consideration, the characteristics and homogeneity of the surface, and atmospheric conditions.

The crop evapotranspiration is estimated by use of the BREB technique from latent heat flux density which is derived from energy balance equation (Equation (2)). For many practical purposes the last three terms are neg- 
ligible and the equation reduces to [6]:

$$
-Q_{s}^{*}=Q_{H}+Q_{E}+Q_{G}
$$

where: $-Q_{s}^{*}$ is the net radiation, $Q_{H}$ is the sensible heat flux which is responsible for heating the atmosphere from the surface up to some $100 \mathrm{~m}$ during the day, except for days with strong convection, $Q_{E}$ is the latent heat energy loss by evapotranspiration and $Q_{G}$ is the vertical heat flux downward into the ground.

On the other hand [4] lists some potential advantages of BREB method, which are:

- non-destructive, direct sampling of the turbulent boundary layer;

- no aerodynamic data are required;

- simple measurement of temperature and vapor pressure at two heights;

- can measure ET over both potential and non-potential surfaces;

- gradient-based fluxes are averaged over a medium sized area (200 - 100,000 m²); automated.

Additionally it is relative simplicity of method made it widely applied [7]-[11].

The Bowen ratio method can be used to access the apportionment of the remaining available energy between the sensible heat term $Q_{H}$ and the latent heat term $Q_{E}$. The Bowen ratio can be determined from the gradients of temperature and vapor pressure above the evaporating surface, using either the equation quoted by [6]:

$$
B=\frac{Q_{H}}{Q_{E}}=\frac{0.62 P}{1000} \frac{T_{2}-T_{1}}{e_{2}-e_{1}}
$$

or that by [12]:

$$
B=\left[\left(\frac{S}{\gamma}+1\right)\left(\frac{T_{w 2}-T_{w 1}}{T_{2}-T_{1}}\right)-1\right]^{-1}=\left[\left(\frac{S}{\gamma}+1\right)\left(\frac{\Delta T_{w}}{\Delta T}\right)-1\right]^{-1}
$$

where:

$B$ = Bowen ratio,

$P=$ atmospheric pressure $(\mathrm{mb})$,

$T_{2}, T_{1}=$ potential temperature $\left({ }^{\circ} \mathrm{C}\right)$ at heights $z_{1}$ and $z_{2}$,

$T_{w 2}, T_{w 1}=$ wet bulb temperatures at $z_{1}$ and $z_{2}$,

$S=\frac{\partial e}{\partial T_{W}}\left[\mathrm{mb} /\left({ }^{\circ} \mathrm{C}\right)^{-1}\right]$ at the mean wet bulb temperature $\bar{T}_{W}$,

$\gamma=$ psychrometric constant,

$$
B=\frac{c_{p}}{\lambda} \frac{\Delta T}{\Delta q}=\frac{c_{p}}{\lambda} \frac{p}{0.622} \frac{\Delta T}{\Delta e}=\gamma \frac{\Delta T}{\Delta e}
$$

where the psychrometric constant is $\gamma=0.667 \mathrm{~K} \cdot \mathrm{hPa}^{-1}$, the pressure $p=1000 \mathrm{hPa}$, the specific heat for constant pressure $c_{p}=1004.834\left[\mathrm{~J} \cdot \mathrm{K}^{-1} \cdot \mathrm{kg}^{-1}\right]$, the evaporation heat of water $\lambda=2500827-2360(T-273.1)\left[\mathrm{J} \cdot \mathrm{kg}^{-1}\right]$, the air density $\rho=\frac{p[\mathrm{hPa}] \cdot 100}{R_{L} \cdot T_{v}}\left[\mathrm{~kg} \cdot \mathrm{m}^{-3}\right]$, and $t=20^{\circ} \mathrm{C}$,

From both Equations (1) and (2), the sensible and latent heat fluxes can be determined:

$$
\begin{gathered}
\frac{-Q_{s}^{*}}{Q_{E}}=\frac{Q_{H}}{Q_{E}}+\frac{Q_{E}}{Q_{E}}+\frac{Q_{G}}{Q_{E}} \\
Q_{E}=\frac{\left(-Q_{s}^{*}-Q_{G}\right)}{B+1} \\
\frac{-Q_{s}^{*}}{Q_{E}}=B+1+\frac{Q_{G}}{Q_{E}} \\
\frac{-Q_{s}^{*}}{Q_{E}}-\frac{Q_{G}}{Q_{E}}=B+1
\end{gathered}
$$




$$
\begin{gathered}
\frac{1}{Q_{E}}\left(-Q_{s}^{*}-Q_{G}\right)=B+1 \\
Q_{H}=\left(-Q_{s}^{*}-Q_{G}\right) \frac{B}{B+1}
\end{gathered}
$$

The latent heat flux can also be expressed as $Q_{E}=\lambda E$, where $\lambda \approx 2.45 \times 10^{6} \mathrm{~J} \cdot \mathrm{kg}^{-1}$ is the latent heat of evaporation/condensation and $E$ is the rate of evaporation/condensation. The accuracy of the Bowen ratio has been discussed by [13] (Tanner, 1960) among others. It is apparent that Equations (7) and (11) do not include the wind velocity and do not prescribe a certain difference between the measurement heights.

The crucial disadvantage of the Bowen-ratio method is that because of the apparent unclosed energy balance the residual is either added to the net radiation or distributed according to the Bowen ratio to the sensible and latent heat flux. In general, the fluxes determined with the Bowen-ratio method are larger than those determined with the eddy-covariance method.

The sensible heat flux can be directly determined with a sonic anemometer and a correction of the buoyancy flux [14] (Liu and Foken, 2001). The Bowen ratio can be calculated with Equation (3), and the latent heat flux can be calculated with:

$$
Q_{E}=\frac{Q_{H}}{B}
$$

\section{Meteorological Methods and the Plant Microclimate}

\subsection{The Plant Microclimate}

The physical processes of the atmosphere, called meteorological processes, establish the existing climate or microclimate. Although it does not act alone, climate, in turn, determines the regime of soils and plants at a given location. Wind, precipitation, sunshine, temperature, humidity, and soil moisture are the primary factors involved. The profitable production of crops and efficient use of water require a microclimate suitable for plant growth. What makes the microclimate suitable? The meteorological methods are helping us answer this question. Recent studies of the nature of the microclimate have yielded a wealth of information on the interaction of the physical processes of the environment and the response of plants to these processes. A brief review of the results from these studies will be presented here [15]-[18]. The meteorological processes are dynamic, each reacting to the changes in the others. The dynamic balance involves a continual exchange of mass and energy. Of particular importance to us are the exchanges of molecular heat energy, radiant energy, momentum, water vapor, carbon dioxide, and oxygen between the plant or soil surface and the atmosphere. We refer to this exchange as the vertical flux of the respective quantities. The meteorological method currently offers one of the best approaches to the study of these fluxes. It also permits an evaluation of the rates of the associated plant physiological processes such as photosynthesis and transpiration under natural field conditions [5].

The energy exchange processes are basic to the rest of the dynamic system. The sun provides the source of radiant energy called solar radiation. Of the total solar energy reaching the outer edge of the earth's atmosphere, about, $65 \%$ is available at the earth's surface for processes requiring an energy input. The other $35 \%$ is reflected by the atmosphere and the earth's surface. The solar energy absorbed by the earth causes it to be warmed. The heated surface emits thermal radiation back into space, resulting in a loss of energy and a cooling of the surface. We refer to the portion of the radiant energy absorbed at the surface and remaining after the emitted thermal radiation portion is subtracted as the net radiation component. This is the important component so far as the energy-utilizing processes at the earth's surface are concerned because it is partitioned among the various physical and physiological processes existing here [5].

Net radiation can be measured with reliable instruments. In the absence of direct measurements, net radiation can be obtained using the radiation balance equation if other components are known. The radiation in the atmosphere is divided into shortwave (solar) radiation and long-wave (heat) radiation [19]. Radiation balance at the surface of the Earth is composed of four spectral radiant fluxes; shortwave down welling irradiation from the Sun $(K \downarrow)$ in the wavelength range $0.15-4 \mu \mathrm{m}$, the amount of energy that is reflected $(K \uparrow)$, the incoming long-wave in the wavelength range from $(4-100 \mu \mathrm{m})$ radiation from the atmosphere $(I \downarrow)$; and the amount of long-wave radiation emitted from the surfaces $(I \uparrow)$ [19]. The net radiation at the ground surface is given by: 


$$
Q_{S}^{*}=K \downarrow+K \uparrow+I \uparrow+I \downarrow
$$

From Equation (13) above we see that the net radiation is the sum of the shortwave down-welling radiation mainly from the sun (global radiation), the long-wave down welling infrared (heat) radiation emitted by clouds, aerosols, and gases, the shortwave up-welling reflected (solar) radiation, and the long wave up-welling infrared (heat) radiation. The shortwave radiation can be divided into the diffuse radiation from the sky and direct solar radiation. The down-welling radiation may be greater if clouds appear in a previously clear sky and the ground surface has cooled. It is only in the case of fog, that up-welling and down-welling radiations are equal. The up-welling long wave radiation is greater than the down-welling long wave radiation, because of the earth's surface is warmer than clouds and aerosols. For clear sky without clouds and dry air, the radiation temperature is approximately $-55^{\circ} \mathrm{C}[19]$.

Expressing this in terms of an energy balance, we can say that the net radiation is equal to the total incoming solar radiation minus that which is reflected and that which is lost by radiation from the surface. We can further say that the net radiation is partitioned among the components: 1) sensible heat, utilized in the heating of the air; 2) latent heat, utilized in the evaporation of water; 3) stored heat in the soil and plant materials; and 4) the photochemical energy, utilized in photosynthesis.

As an example of information gained from studies of the microclimate on the interaction of the radiation energy exchanges and the other processes existing within the microclimate, let us consider what happens within a growing crop on a clear summer day. Beginning at sunrise, the soil and plant surfaces are rapidly heated by the absorption of radiant solar energy. Because the air is nearly transparent to shortwave radiation, it does not absorb as much of the radiant energy as do the surfaces. Therefore, the surfaces are much warmer than the air and there is a resulting flow of heat from the surfaces to the air, referred to as sensible heat flux. Because of this, a strong temperature gradient develops very near the surface and the rising of the warmer air parcels causes the air to become unstable. This greatly increases the mixing motion or turbulence of the airstream, which serves to cool the surface and warm the air at even faster rates.

In addition, the solar energy absorbed provides energy for the evaporation of water from the surface. The increased turbulence of the unstable air increases the rate of transfer of water vapor away from the surface, so that there is a rapid drying of soil surfaces and wilting of plants if moisture is limiting.

During photosynthesis, photochemical energy is used by the crop leaves to synthesize organic matter using carbon dioxide from the air. This results in a net transfer of carbon dioxide from the air to the leaves of the plant. Turbulent air motion enhances this transfer rate [5].

The net result is that the surface gains energy from the sun then loses energy in heating the air, in the evaporation of water and in the flow of heat to the deeper soil layers. This is accompanied by a flow of water vapor away from and a flow of carbon dioxide to, the surface [5].

After sunset, the situation quickly reverses. The surface radiates heat away rapidly and cools to a temperature below that of the air. There is then a flow of heat from the deeper soil layers and from the air to the cooling surface. A strong temperature gradient develops between the air and the soil or plant surface opposite in direction to that existing during the day-time. This condition, called temperature inversion, results in the air mass becoming more stable, with decreased turbulent mixing. Evaporation rapidly decreases, and photosynthesis ceases so there is then an uptake of oxygen and a release of carbon dioxide associated with respiration [5].

The plant and soil surfaces thus act as sources and sinks for the various energy and molecular entities throughout the day. There is a flux of energy and molecular quantities either away from or toward the surface at almost all times, the direction depending upon the daytime conditions. The microclimatic conditions determine the flux rates, but the plant can modify these by stomata closure, shading the ground, and increasing the surface roughness.

Our desire is to be able to quantitatively measure these flux rates on a continuous basis. The meteorological approach serves as a useful tool in enabling us to do this. A complete study of the microclimate involves the measurement of net radiation, total incoming incident radiation, wind speed, air temperature, air humidity, soil temperature, the flow of heat into the soil, the soil moisture content, and the various properties of the surface or plant community itself [5].

\subsection{The Meteorological Approach}

The meteorological approach to determining the vertical flux of energy and mass from a crop surface requires 
the measurement of the respective gradients, with height, of the energy and molecular entities and the determination of a transfer coefficient. The plant and soil surfaces acting as sources and sinks for the various entities establish the concentration or energy differences, which we call gradients, along which the respective entities are transferred.

The transfer rate, or flux, of the particular entity is related to its gradient by a transfer coefficient. This coefficient, which is similar to a diffusion coefficient, characterizes more than any other single parameter the effectiveness of the exchange process [5].

Of particular interest to the micrometeorologist is the flux of carbon dioxide and water vapor associated with photosynthesis and evapotranspiration. The evaporation rate can be calculated under natural field conditions without altering the crop or soil system from measurements of the water vapor gradient and the transfer coefficient. Short period results so necessary in the evaluation of the important aspects of the highly transient system are possible. The meteorological approach also lends itself to mobility. It does, however, require careful application, considerable instrumentation, and involved analysis procedures. Recent advances in instrumentation, electronic technology, and computer developments have enabled use of this approach in spite of its complexity [5]. However, an example of one of the meteorological methods is presented to show how they can be applied to problems of crop production and water-use efficiency [5].

The energy balance approach is a suitable example because of its basic nature and its prominence in studies of evapotranspiration. This approach involves determination of the partitioning of energy among the various physical processes contributing to the microclimate, and can be used to measure daily evaporation with little more effort than that required to measure weekly evaporation by soil moisture sampling methods. It has been applied to the determination of evapotranspiration from crops only within the past few years [13].

\section{The Energy Balance Method}

A brief theory of the energy balance is presented here to illustrate what is involved in using such a method. In the total balance, the earth's surface receives more radiation energy than is lost, i.e. the net radiation at the ground surface is positive $-Q_{s}^{*}$. The surplus of supplied energy will be transported back to the atmosphere due to two turbulent energy fluxes, the sensible heat flux $Q_{H}$ and the latent heat flux $Q_{E}$, A small portion of the net radiant energy is utilized in the photochemical processes of photosynthesis. A larger portion goes into the heating of the soil, plants, and air. A fairly large portion provides evaporation. Furthermore, energy is transported into the soil due to the ground heat flux $Q_{G}$ and will be stored by plants, buildings, etc. $\Delta Q_{S}$. The sensible heat flux is responsible for heating the atmosphere from the surface up to some $100 \mathrm{~m}$ during the day, except for days with strong convection. A simplified energy balance equation for a crop community, neglecting the relatively small photosynthetic energy component and assuming horizontal uniformity, can be written as Equatian (2) above.

The terms for sensible heat and latent heat can also be represented by diffusion type equations:

$$
\begin{gathered}
Q_{H}=-\rho C_{p} K_{H} \frac{\partial T}{\partial z} \\
Q_{E}=-\rho \lambda K_{E} \frac{\partial q}{\partial z}
\end{gathered}
$$

where $\rho$ : the air density $\left(\mathrm{g} \cdot \mathrm{cm}^{-3}\right) ; C_{p}$ : the specific heat capacity for constant pressure $\left(\mathrm{calg}^{-1}\right) ; \lambda$ : evaporation heat of water; $K_{H}$ heat transfer coefficient $\left(\mathrm{cm}^{2} \cdot \mathrm{s}^{-1}\right) ; K_{E}$ water vapor transfer coefficient; $\mathrm{Z}$ height above ground (cm); and $T$ temperature $\left({ }^{\circ} \mathrm{C}\right)$.

The ground heat $Q_{G}$, is based mainly on molecular heat transfer, and is proportional to the temperature gradient times the thermal molecular conductivity $a_{G}$

$$
Q_{G}=a_{G} \frac{\partial T}{\partial z} \text {. }
$$

This molecular heat transfer is so weak that during the day only the upper decimeters are heated. When considering the annual cycle of ground temperature, maximum temperature is at the surface during the summer, but 10 - $15 \mathrm{~m}$ below the surface during winter [20]. Table 1 shows different values for different thermal molecular conductivity $a_{G}$ of Equation (16). 
Table 1. Thermal molecular conductivity $a_{G}$, volumetric heat capacity $C_{G}$, and molecular thermal diffusivity $v_{T}$ for different soil and ground properties [21].

\begin{tabular}{cccc}
\hline Ground surface & $a_{G}\left(\mathrm{~W} \cdot \mathrm{m}^{-1} \cdot \mathrm{K}^{-1}\right)$ & $C_{G}\left(10^{6} \mathrm{~W} \cdot \mathrm{s} \cdot \mathrm{m}^{-3} \cdot \mathrm{K}^{-1}\right)$ & $v_{T}\left(10^{-6} \mathrm{~m}^{2} \cdot \mathrm{s}^{-1}\right)$ \\
\hline rocks (granite) & 2.73 & 2.13 & 1.28 \\
moist sand (40\%) & 2.51 & 2.76 & 0.91 \\
dry sand & 0.30 & 1.24 & 0.24 \\
sandy clay (15\%) & 0.92 & 2.42 & 0.38 \\
swamp (90\% water) & 0.89 & 3.89 & 0.23 \\
old snow & 0.34 & 0.84 & 0.40 \\
new snow & 0.02 & 0.21 & 0.10 \\
\hline
\end{tabular}

From Equation (16) the determination of $Q_{G}$ is not practicable because the temperature profile must be extrapolated to the surface to determine the partial derivative there. This can be uncertain because of the high temperature gradients near the surface and the difficulties in the determining thermal heat conductivity. According to [22] using sensitivity analysis, the soil heat flux plate should be buried rather deeply $(10-20 \mathrm{~cm})$ with some temperature measurements (water protected thermometers) made above it to calculate the heat storage. A similar accuracy can be archived if a temperature profile is used to calculate both the soil heat flux according to Equation (16) at a certain depth and the heat storage between this depth and the surface [19].

The heat exchange in the air due to turbulence is much more effective. This is because turbulent exchange occurs over scales of motions ranging from millimeters to kilometers. Turbulent elements can be thought of as air parcels with largely uniform thermodynamic characteristics. Small-scale turbulence elements join to form larger ones and so on. The largest eddies are atmospheric pressure systems. The heated turbulent elements transport their energy by their random motion. The larger turbulent elements receive their energy from the mean motion, and deliver the energy by a cascade process to smaller elements. Atmospheric turbulence is a specialty of the atmospheric motion consisting in the fact that air volume (much larger than molecules: turbulent elements, turbulent eddy) achieve irregular and stochastic motions around a mean state. They are of different order with characteristic extensions and lifetimes ranging from centimeters and seconds to thousands of kilometers and days [19].

The characteristic distribution of turbulent elements (turbulent eddies) takes place according to their size and is represented by the turbulence spectrum: The turbulence spectrum is a plot of the energy distribution of turbulent elements (turbulent eddies) according to their wavelength or frequency. Depending on the frequency, the distribution is classified as macro, meso or micro turbulence (Foken, 2008). Turbulence refers to the apparently chaotic nature of many flows, which is manifested in the form of irregular, almost random fluctuations in velocity, temperature, and scalar concentrations around their means values in time and space [23]. The calculation of the heat fluxes (sensible and latent) caused by turbulent elements is analogous to Equation (16) using the vertical gradients of temperature $T$ and specific humidity $q$ respectively. The sensible heat flux, $Q_{H}$, describes the turbulent transport of heat from and to the earth's surface.

Turbulent transfer is a bulk transfer, so the transfer coefficients $K_{H}$ and $K_{E}$ are nearly equal because they are not as much a function of molecular properties as are molecular diffusion coefficients. Substitution of Equations (14) and (15) for the sensible and latent heat terms of Equation (2) and solving for the latent heat term gives:

$$
Q_{E}=\frac{-\left(Q_{s}^{*}+Q_{G}\right)}{1+\frac{C_{p}}{\lambda}\left(\frac{\partial T / \partial z}{\partial q / \partial z}\right)}
$$

Therefore, if we measure the net radiation, soil heat storage, and the air temperature and humidity gradients all of which we are presently able to do, then we can calculate the latent heat flux and water vapor flux which gives the evaporation rate. 


\section{The Application of Meteorological Methods}

The energy balance method has much potential in the study of rate of evaporative loss of water from cropped surfaces because of its fundamental nature and because it can be employed in various other forms. It lends itself to estimating evapotranspiration by approximation procedures when complete data are not available. Such approaches have been suggested and successfully used by [24].

The meteorological methods serve as tools for increasing crop production and water-use efficiency by providing a means of obtaining fundamental information about the controlling physical processes involved in the microclimate.

The economic use of water, for example, requires knowledge of the water evaporated by various vegetated or treated surfaces. It requires an understanding of the effects of stage of growth, plant characteristics, and various management practices on water use and crop production. An understanding of plant response to the microclimate in the evaporation of water is necessary for predicting the amount of water that will be evaporated under given conditions and for controlling evaporation [5].

Furthermore, the meteorological method has a potential for more direct application to these problems. It was suggested several decades ago that the careful determination of evaportranspiration by such a method could be used to determine the time to irrigate [25] (Van Bavel, 1956). This has been tested on an experimental basis and found to be a usable technique. With more information about crop factors and their relationship to water use, the utility of this approach will be increased [5].

As a further development along this line, the scheduling of irrigation of several crops on farms in this area is now being cooperatively carried out on a trial basis. The scheduling is based on meteorological parameters and previously obtained information about the response of crops to certain conditions [5].

This procedure offers an alternative to present methods of determining when to irrigate. The method most commonly used is that of judging irrigation needs by the plant or soil appearance, which often results either in irrigation after the plant has already suffered from lack of water or in the waste of water by irrigating before it is required. Another method is that of using soil moisture measuring instrumentation or sampling procedures to monitor the water content of the soil. These methods can be used satisfactorily on a research basis or on largescale operations where individuals highly skilled in the interpretation of these instruments are available. However, it is not likely that these instruments will ever be used extensively on the small farming scale. It is highly probable that within the near future the meteorological approach will find widespread application and that with further developments it may be possible to forecast irrigation requirements from crop data, meteorological data, and predicted weather patterns.

Meteorological methods may also be used to study the effects of irrigation on the microclimate and the plant response to these effects. Irrigation decreases air and soil temperatures and increases the humidity of the atmosphere near the surface. It, therefore, exerts a profound influence upon the disposition of energy at the surface and upon the climate near the ground. Such side effects of irrigation may have great importance in the management of suitable microclimates [5].

Another interesting application is that of studying the modification of the microclimate by such management practices as planting of windbreaks. In another application, the meteorological approach has been used to gain valuable information about the distribution of photosynthesis within a crop throughout the day [26] [27]. Information gained from these studies could lead to the development of an ideal model of a plant so far as leaf arrangement, leaf characteristics and other plant morphological characteristics are concerned. This might help plant breeders in the development of improved plants [5].

\section{Conclusions}

The probable advent of increasing water scarcity in this century will see less increase in irrigated land available for food production than in the past. Novel irrigation technologies need to be tested under local environments and particular agricultural production systems of developing countries like Nigeria. While irrigation can benefit yields and enhance in water-limited environments, the potential for full irrigation is decreasing, with increased competition from the domestic and industrial sectors. Thus the main challenge confronting both rain fed and irrigated agriculture is to improve sustainable water use for agriculture. This can be achieved through 1) an increase in crop water productivity (an increased in marketable crop yield per unit of water taken up by crop), 2) a decrease in water outflows from the plant rooting zone other than that required by plants and 3) an increase in 
soil water storage within the plant rooting zone through better soil and water management practices at farm and catchment scales.

The micrometeological method of studying the microclimate and all its important physical processes is serving as a useful tool for gaining information about these processes. With this information, we will be better able to predict the response of plants as we alter the natural environmental conditions in an attempt to provide an ideal environment for plant growth. Also, the micrometeorological method may in the near future serve as the basic tool by which we manage our crops and decide when to irrigate our agricultural lands (Wright and Lemon, 1967).

\section{References}

[1] Thornthwaite, C.W. (1948) An Approach toward a Rational Classification of Climate. Geographical Review, 38, 55-94. http://dx.doi.org/10.2307/210739

[2] Tucci, C.E.M. and Beltrame, L.F.S. (2009) Evaporação e evapotranspiração, In: Tucci, C.E.M., Ed., Hidrologia: Ciência e Aplicação, UFRGS Editora, Porto Alegre, 253-287.

[3] Allen, G.R., Pereira, S.L., Raes, D. and Smith, M. (1998) Crop Evapotranspiration: Guidelines for Computing Crop Water Requirements. Food and Agrocultural Organization of the United Nations, FAO-56, Rome, $300 \mathrm{p}$.

[4] Allen, R.G., Pereira, L.S., Howell, T.A. and Jensen, M.E. (2011) Evapotranspiration Information Reporting: I. Factors Governing Measurement Accuracy. Agricultural Water Management, 98, 899-920. http://dx.doi.org/10.1016/j.agwat.2010.12.015

[5] Wright, J.L. and Lemon, E.R. (1967) Micrometeorological Methods as Tools for Increasing Crop Production and Water-Use Efficiency. Proceedings of 8th Annual Fertilizer Conference of the Pacific Northwest, Twin Falls, 11-13 July 1967.

[6] Munn, R.E. and Davidson, B. (1957) Exploring the Atmosphere’s. Pergamon Press, New York, 376 p.

[7] Bezerra, J.R.C., de Azevedo, P.V., da Silva, B.B. and Dias, J.M. (2010) Evapotranspiração e coeficiente de cultivo do algodoeiro BRS-200 Marrom, Irrigado. Revista Brasileira de Engenharia Agrícola e Ambiental, 14, 625-632. http://dx.doi.org/10.1590/S1415-43662010000600009

[8] Gavilán, P. and Berengena, J. (2007) Accuracy of the Bowen Ratio-Energy Balance Method for Measuring Latent Heat Flux in a Semiarid Advective Environment. Irrigation Science, 25, 127-140. http://dx.doi.org/10.1007/s00271-006-0040-1

[9] Hou, L.G., Xiao, H.L., Si, J.H., Zhou, M.X. and Yang, Y.G. (2010) Evapotranspiration and Crop Coefficient of Populus euphratica Olivi Forest during the Growin Season in the Extreme arid Region Northwest China. Agricultural Water Management, 97, 351-356.

[10] Steduto, P. and Hsiao, T.C. (1998) Maize Canopies under Two Soil Water Regimes: IV. Validity of Bowen RatioEnergy Balance Technique for Measuring Water Vapor and Carbon Dioxide Fluxes at 5-min Intervals. Agricultural and Forest Meteorology, 89, 215-228.

[11] Todd, R.W., Evett, S.R. and Howell, T.A. (2000) The Bowen Ratio-Energy Balance Method for Estimating Latent Heat Flux of Irrigated Alfalfa Evaluated in a Semi-Arid, Advective Environment. Agricultural and Forest Meteorology, 103, 335-348. http://dx.doi.org/10.1016/S0168-1923(00)00139-8

[12] Sergeant, D.H. and Tanner, C.B. (1967) A Simple Psychrometric Apparatus for Bowen Ration Determinations. Journal of Applied Meteorology, 6, 414-418.

[13] Tanner, C.B. (1960) Energy Balance Approach to Evapotranspiration from Crops. Soil Science Society of America Journal, 24, 1-9. http://dx.doi.org/10.2136/sssaj1960.03615995002400010012x

[14] Liu, H. and Foken, T. (2001) A Modified Bowen Ratio Method to Determine Sensible and Latent Heat Fluxes. Meteorologische Zeitschrift, 10, 71-80. http://dx.doi.org/10.1127/0941-2948/2001/0010-0071

[15] Geiger, Z.R. (1959) The Climate near the Ground. 2nd Edition, Harvard University Press, Cambridge, MA, 482 p.

[16] Slatyer, R.O. and Mcllroy, I.C. (1961) Practical Microclimatology. UNESCO, Prepared and Reproduced by CSIRO, Australia.

[17] Waggoner, P.E., Ed. (1965) Agricultural Meteorology. American Meteorological Society, Boston, 188 p.

[18] Evans, L.T. (1962) Environmental Control of Plant Growth. Academic Press, New York, 449 p.

[19] Foken, T. (2008) Micrometeorology. Springer-Verlag, Berlin, 306 p.

[20] Lehmann, A. and Kalb, M. (1993) 100 Jahre meteorologische Beobachtungen an der Säkularstation Potsdam 18931992. Deutscher Wetterdienst, Offenbach, 32 p. 
[21] Stull, R.B. (1988) An Introduction to Boundary Layer Meteorology. Kluwer Academic Publishers, Dordrecht, Boston and London, 666 p. http://dx.doi.org/10.1007/978-94-009-3027-8

[22] Liebethal, C. and Foken, T. (2007) Evaluation of Six Parameterization Approaches for the Ground Heat Flux. Theoretical and Applied Climatology, 88, 43-56. http://dx.doi.org/10.1007/s00704-005-0234-0

[23] Arya, S.P. (2001) Introduction to Micrometeorology. Academic Press, San Diego, 415 p.

[24] Jensen, M.E. and Haise, H.R. (1963) Estimating Evapotranspiration from Solar Radiation. Journal of the Irrigation and Drainage Division, 89, 15-41.

[25] Van Bavel, C.H.M. (1956) Evapotranspiration, the ET Method, a New Way to Find a Right Time to Irrigate. Better Farming Methods, April 1956, 14.

[26] Wright, J.L. and Lemon, E.R. (1966) Photosynthesis under Field Conditions. VIII. Analysis of Windspeed Fluctuation Data to Evaluate Turbulent Exchange within a Corn Crop. Agronomy Journal, 58, 255-261. http://dx.doi.org/10.2134/agronj1966.00021962005800030004x

[27] Wright, J.L. and Lemon, E.R. (1966) Photosynthesis under Field Conditions. IX. Vertical Distribution of Photosynthesis within a Corn Crop. Agronomy Journal, 58, 265-268. http://dx.doi.org/10.2134/agronj1966.00021962005800030006x. 